NASA Technical Memorandum 100114

AIAA-87-2050

\title{
The Supersonic Through-Flow Turbofan for High Mach Propulsion
}

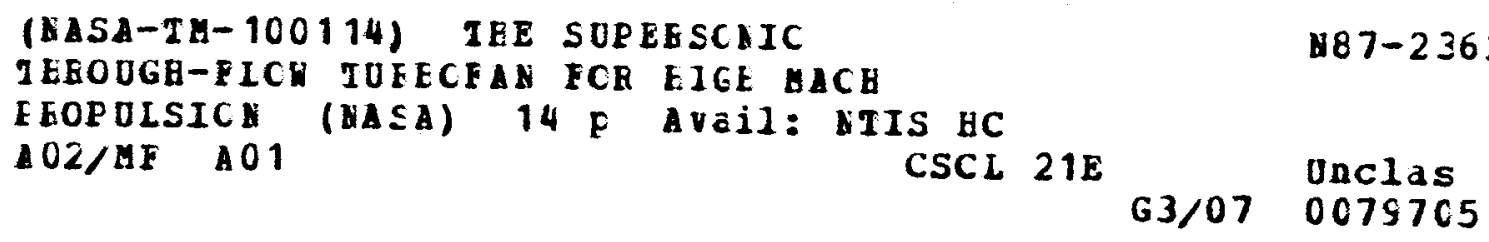

Leo C. Franciscus

Lewis Research Center

Cleveland, Ohio

Prepared for the

23rd Joint Propulsion Conference cosponsored by the AIAA, SAE, ASME, and ASEE

San Diego, California, June 29-July 2, 1987 
THE SUPERSONIC THROUGH-FLOW TURBOFAN

FOR HIGH MACH PROPULSION

by

Leo C. Franciscus

National Aeronautics and Space Administration

Lewis Research Center

21000 Brookpark Road

Cleveland, Ohto 44135

ABSTRACT

A study was made to evaluate the potential improvements in aircraft turbine engine performance by incorporating unique supersonic through-flow fans. Engine performance, weight, and mission studies were carried out for conventional turbofan engines and for turbofan engines using supersonic through-flow fans. A Mach 3 commercial transport mission was considered. The advantages of the supersonic fan engines were evaluated in terms of mission range comparisons between the supersonic fan engines and the conventional engines. The installed specific fuel consumption of the supersonic fan engines was 12 percent better than the conventional engines and the installed weight was projected to be 25 percent lighter. For the takeoff gross weight of 550000 pounds, the aircraft powered by supersonic fan engines had a range capability of $6600 \mathrm{n} \mathrm{mi}$ compared to 5300 $n \mathrm{mi}$ (a 25 percent improvement) for the conventional engines.

\section{NOMENCLATURE}

\begin{tabular}{|c|c|}
\hline $\begin{array}{l}\text { BPR } \\
\text { CET } \\
\text { F } \\
\text { FPR } \\
\mathrm{ft}\end{array}$ & $\begin{array}{l}\text { bypass ratio } \\
\text { combustor exit temperature, }{ }^{O} R \\
\text { thrust, ibf } \\
\text { fan pressure ratio } \\
\text { feet }\end{array}$ \\
\hline g & $\begin{array}{l}\text { gravitational acceleration, } 32.174 \\
\mathrm{ft} / \mathrm{sec}^{2}\end{array}$ \\
\hline $\mathrm{hr}$ & hour \\
\hline $1 \mathrm{bm}$ & pound mass \\
\hline & $\begin{array}{l}\text { pound force } \\
\text { Mach number }\end{array}$ \\
\hline $\begin{array}{l}n \mathrm{mi} \\
\text { OPR } \\
\mathrm{R}\end{array}$ & $\begin{array}{l}\text { nautical mile } \\
\text { engine overall pressure ratio } \\
\text { radius }\end{array}$ \\
\hline $\begin{array}{l}\text { SfC } \\
\text { TAUG } \\
\text { TOGW }\end{array}$ & $\begin{array}{l}\text { specific fuel consumption } 1 \mathrm{bm} / \mathrm{hr} / 1 \mathrm{bf} \\
\text { augmentor temperature, }{ }^{\mathrm{R}} \mathrm{R} \\
\text { takeoff gross weight, } 1 \mathrm{bm}\end{array}$ \\
\hline W & $\begin{array}{l}\text { tan tip speed, } \mathrm{t} / \mathrm{sec} \\
\text { weight, } 1 \mathrm{bm}\end{array}$ \\
\hline & length, ft \\
\hline
\end{tabular}

\section{Subscripts}

$\begin{array}{ll}\text { AB } & \text { absolute } \\ C & \text { cowl } \\ \text { ENG } & \text { engine } \\ \text { MAX } & \text { maximum } \\ 0 & \text { ambient }\end{array}$

\section{INTRODUCTION}

In the 1970's, NASA sponsored studies by Pratt and Whitney Aircraft and the General Electric Company to identify propulsion systems that would be suitable for long-range supersonic cruise aircraft. 1-7 These studies considered a variety of conventional and variable cycle concepts. An alternative concept, the supersonic through-flow fan variable-bypass engine, was suggested by Advanced Technology Laboratory Inc. and was studied under NASA contract.8 This engine (fig. 1) incorporates a single-stage supersonic through-flow fan. This type of fan has supersonic axial Mach numbers at the fan face and stator exit. The results of the studies by Advanced Technology Laboratories Inc. indicated that this type of engine may be a more efficient powerplant for supersonic cruise aircraft than the more conventional engines. Additional studies at NASA Lewis showed similar attractive results. 9-10

For the long supersonic cruise range considered in these studies, a large part of the advantage of this engine is attributed to the improvement in installed supersonic cruise $\mathrm{sfc}^{\prime} \mathrm{s}$ which is due in large part to the reduced inlet losses. Also, it has the potential for increased dry thrust compared to a conventional engine and reduced inlet and nacelle weight.

The studies of this engine for supersonic cruise have recently been extended to the high Mach regime (Mach 3-5). The initial results for the Mach 3 studies are presented in this paper.

This study encompassed aircraft with extended supersonic cruise range. Two types of engines were considered in the study: a dry supersonic through-flow fan turbofan and a conventional dry mixed flow turbofan. The engines are compared on the basis of mission range for an aircraft of fixed takeoff gross weight.

\section{METHOD OF ANALYSIS}

The study reflected differences in engine thrust and sfc, pod drag, and propulsion system weight. Mission performance calculations were made to determine mission range as a function of sea level static thrust/gross weight for a fixed takeoff gross weight and payload. 
The engine concepts are shown in figure 1 . Engine cycle characteristics and weight are shown in Table I for JP type fuel.

The supersonic fan engine is similar to a two-spool conventional turbofan except for the inlet and fan. The supersonic fan is a supersonic through-flow fan stage, i.e., supersonic axial Mach numbers at the fan face and stator exit. The supersonic fan would lead to improvements in the overall propulsion system. These improvements are a reduction in fan weight (single-stage vs. multi-stage), reductions in inlet losses (at supersonic flight), and inlet weight, and more flexibility in matching the engine cycle to the airplane thrust requirements.

The engine technology assumed in the study is similar to goals of the Department of Defense Integrated High Performance Turbine Engine Technology Plan (IHPTET). This technology is characterized by near stoichiometric combustor exit temperatures and advanced materials to provide major improvements in engine thrust/weight ratio.

The installed engine performance for the engines was computed with the engine cycle computer program of reference 11 which performs cycle calculations, design, and of $f$-design on a component by component basis. Except for the supersonic fan, the component aerodynamic characteristics, efficiencies, and cooling requirements for conventional fans, compressors, turbines, combustors, etc. used in the program were the same for both engines. The supersonic fan aerodynamic design was computed using a mean line one-dimensional analysis provided by the NASA Lewis Turbine and Rotary Engine Technology Branch. The aerodynamic characteristics of the supersonic fan are shown in figure 2 compared to the conventional fan aerodynamics. The operating lines for the fans are also shown in the figure. In this study, it was assumed that the inlet airflow in front of the supersonic fan face was "started" at sea level static. As shown in the figure, the fan was designed for a fan face Mach number of 1.5 at sea level static. Several concepts for achieving supersonic flow at these conditions (movable geometry inlet, variable fan inlet guide vanes, bleed) are currently under analysis at NASA Lewis. Another approach would be to maintain subsonic velocities at the fan face and start both the inlet and fan at some supersonic flight speed. The operating lines were determined by matching the engine cycles with airflow schedule for each flight condition. As seen in the figure at the Mach 3 cruise flight condition, the fan face Mach number is 2.5 and the pressure ratio is about 2.

The inlet performance for the conventional engine was obtained from reference 12 . Inlet design and performance studies for the supersonic fan are currently underway at the NASA Lewis Advanced Planning and Analysis Office. Two supersonic through-flow inlet designs have been studied thus far and are shown in figure 3 compared to a conventional inlet. These inlets were studied using a method-of-characteristics analysis. For the variable area design a minimum area is provided (supersonic) to allow for possible movable geometry for starting and stability. For the constant area design, studies are proceeding to determine the off-design starting and stability characteristics of this inlet. As shown in the figure, the total pressure recovery for the supersonic through-flow inlets are 0.96 compared to 0.9 for the onventional inlet. It is also seen that the lengths are about one half that of the conventional inlet, representing a sizeable savings in drag and weight. The inlet drag for these inlets was determined using the methods of references 13 and 14 . The constant area supersonic through-flow inlet was selected for the supersonic fan engines in this study. The performance for the supersonic through-flow inlet and the conventional inlet are shown in figures 4 through 6 . The performance includes friction, spillage bleed drag, and shock losses. It was assumed that the supersonic through-flow inlet would not require boundary layer bleed since the inlet is so short and would not have the strong adverse pressure gradients of conventional inlets. This represents a sizeable drag reduction as seen by comparing figures 4 and 5 . The total inlet drag for both inlets is compared in figure 6 . At Mach 3, cruise the conventional inlet total drag is about four times greater than that of the supersonic through-flow inlet. For the core diffuser of the supersonic fan engine, a total pressure recovery of 85 percent was assumed and a 10 percent boundary layer bleed were included in the engine cycle and performance analysis.

Engine weight estimates for the conventional engines and the core of the supersonic fan engines were calculated from references 15 and 16. The core diffuser weight was scaled from the data in reference 9. Weight estimates for the conventional and supersonic through-flow inlets and nacelles were estimated by the methods of reference 14 .

The airplane used in the study, figure 7 , was derived from a NASA Langley concept. 17' The airplane takeoff gross weight is 550000 pounds. The 60000 payload and the airplane empty weight without the weight of the propulsion system remained fixed. The mission range varied with changes in engine performance and weight.

The mission is shown in figure 8 and the climb/acceleration path is shown in figure 9. The mission is an all supersonic cruise mission. The total range is the sum of the climb/acceleration cruise and descent. Fuel reserves include an enroute contingency of 5 percent of the mission fuel and provisions for a 20-minute loiter.

\section{RESULTS AND DISCUSSION}

Engine Performance and Weight - As mentioned previously, the cycle characteristics of the supersonic fan engine lead to improvements in propulsion system performance. In addition to lower inlet losses (fig. 6), the cycle can be matched to improve the thrust lapse. In conventional bypass engines, the bypass ratio increases with flight Mach number leading to SFC 
penalties and lower thrust. For the supersonic fan engine, the bypass ratio escalation is reduced leading to higher specific thrust and improved sfc's.

Three versions of the supersonic fan engine were studied; sea level static design bypass ratios of $1.5,2.0$, and 2.5 . Figure 10 shows the installed performance of these engines compared to the conventional mixed flow turbofan at Mach 3. The specific thrust is the thrust divided by the sea level static corrected airflow. It is seen that for the bypass ratio 2.5 engine, the maximum thrust of the supersonic fan engine is about 40 percent higher than the conventional engine. The specific fuel consumption is about 12 percent lower. The part power operation of the supersonic fan engines is more efficient (less-sfc penalty at reduced thrust) than that of the conventional fan. This is due in part to the lower operating bypass ratio of the supersonic fan and the benefits of mixed flow for the conventional turbofan become less at lower turbine inlet temperatures.

Comparisons of the propulsion weight for the engines is shown in figure 11. For the same bypass ratio of 2.5 , the engine plus nozzle weight is about the same for the conventional and supersonic fan engines. This is mainly because the supersonic fan engine is a separate flow turbofan with two nozzles. In this study, the biggest savings in propulsion weight is due to the short supersonic through-flow inlet. It should be pointed out that the weights for the conventional and supersonic through-flow inlets were calculated assuming the same degree of complexity. Should the supersonic through-flow inlet be a simpler device then the weights could be even less.

Mission Studies - Mission studies were performed for the three supersonic fan engines and the conventional engine. The results in terms of range versus engine sea level static corrected airflow (engine size) are shown in figure 12. For a given engine type, too large of an engine results in a weight penalty and lower range. Too small of an engine results in excessive acceleration/climb fuel consumption and lower range. Comparing the three supersonic fan engines, the maximum range is about the same, but the engine size for maximum range increases with increasing design bypass ratio due to the decrease maximum thrust. This trend is typical of dry bypass engines. For the conventional engine, the range is more sensitive to engine size than for the supersonic fan engines because of the heavier engine weight. The maximum range with the conventional engine is $5300 \mathrm{n} \mathrm{mi}$ The supersonic fan engine would improve the range by about 25 percent.

\section{ON-GOING AND PLANNEd RESEARCH}

Figure 13 shows some of the key supersonic through-flow areas of research. Fan aero dynamic studies are being conduct at NASA Lewis and at the United Technology Research Center under NASA contract. Plans include testing a model fan stage at NASA Lewis in the summer of 1988. One of the major items under study is starting the fan. Supersonic through-flow inlet designs are being studied at NASA Lewis. The inlets discussed in this paper are very preliminary designs. On-going and future studies will be focused on inlet starting and the degree of simplicity that can be achieved while retaining acceptable performance. core inlet research for the supersonic fan turbofan will include boundary layer stability and bleed requirements and aero studies to determine variable geometry requirements. Alternate cycles such as the ATR and supersonic aft fan turbofan would not require core inlet research. For the cruise speed and technology level assumed in this study, augmentation is not required. At high cruise speeds above about Mach 4, thrust augmentation will probably be required. Preliminary analys is of supersonic combustion in the duct stream at a Mach 5 cruise speed has indicated that supersonic combustion may be a viable means of augmenting the supersonic through-flow fan engine; however, this needs further study. Studies are also continuing to investigate alternate cycles such as the air turboramjet that could be enhanced by the supersonic through-flow compressor. Additional studies are needed to investigate other alternate supersonic fan cycles and aircraft/missions.

\section{SUMMARY}

A study was made to evaluate the potential benefits of supersonic through-flow fan engine concepts for commercial supersonic cruise aircraft. Engine performance, weight, and aircraft mission studies were carried out for the supersonic through-flow fan engine concepts and for a conventional mixed flow turbofan engine concept. The advantages of the supersonic fan engines were evaluated in terms of mission range comparisons between the supersonic fan engines and the conventional turbofan engine. A Mach 3 a) supersonic cruise mission was used in the study. The aircraft simulated in the mission studies was derived from a NASA Langley arrow wing concept. The specific fuel consumption of the supersonic fan engines was calculated to be 12 percent lower than of the conventional turbofan. The propulsion system weight of the supersonic fan engines was estimated to be about 25 percent less. The mission range of the aircraft powered by supersonic fan engines achieved 25 percent,more range than aircraft powered by the conventional engines.

\section{REFERENCES}

1. Sabatella, 3. A., ed.: Advanced Supersonic Propulsion Study, (P\&W TM-4871, Pratt \& Whitney Aircraft, NAS3-16948), NASA CR-134633, 1974

2. Szeiliga, $R$, and Allan R. D.: Advanced Supersonic Technology Propulsion Study, (R74AEG330, General Electric Co., NAS3-16950), NASA CR-134904, 1975

3. Howlett, R. A., et al: Advanced Supersonic Propulsion Study Phase II, Final Report, 
(PWA-5312, Pratt \& Whitney Aircraft, NAS3-16948), NASA CR-134904, 1975

4. Allan, R. D.: Advanced Supersonic Propulsion System Technology Study, Phase II Final Report, (B75AEG508), General Electric Co., NAS3-16950), NASA CR-134913, 1976

5. Howlett, R. A., et al: Advanced Supersonic Propulsion Study, Phase III, Final Report, (PWA-5461), Pratt \& Whitney Aircraft, NAS3-19540), NASA CR-135148, 1976

6. Howlett, R. A. and streicher F. D.: Advanced Supersonic Propulsion Study, Phase IV, Final Report, (PWA-5547-4), Pratt \& Whitney Aircraft, NAS3-19540, NASA CR-13523, 1977

7. Allan, R. D. and Joy, W.: Advanced Supersonic Propulsion System Study, Phase III and IV, Final Report, (R77AE635, General Electric Co., NAS3-19544 Modification 4), NASA CR-135236, 1977

8. Trucco, H: Study of Variable Cycle Engines Equipped With Supersonic Fans, Final Report, ATL TR 201 Advanced Technology Laboratories Inc., NAS3-17559, NASA CR-134777, 1975

9. Franciscus, L. C.: Supersonic Through-Flow Fan Engines for Supersonic Cruise Aircraft, NASA TM-78889, 1978

10. Franciscus, L. C.: Supersonic Fan Engines for Military Aircraft, NASA TM-83499, 1983

TABLE I - - STUDY ENGINE CHARACTERISTICS

\begin{tabular}{|l|c|c|}
\hline & $\begin{array}{c}\text { Conventional } \\
\text { turbofan }\end{array}$ & $\begin{array}{c}\text { Supersonic } \\
\text { through-flow } \\
\text { turbofans }\end{array}$ \\
\hline$W \sqrt{\theta / \delta}, 1 \mathrm{bm} / \mathrm{sec}$ & 500 & 500 \\
OPR & 40 & 40 \\
FPR & 3.3 & 3.3 \\
BPR & 2.5 & $1.5,2.0,2.5$ \\
CET nax, ${ }^{\circ} \mathrm{R}$ & 4500 & 4500 \\
Fan stages & 3 & 1 \\
(F/WENG)sis & $\mathrm{a} 7$ & $\mathrm{a} 7$ \\
\hline
\end{tabular}

anlet weight not included.
11. Fishbach, L. H. and Caddy, M. J.: NNEP--The Navy-NASA Engine Program, NASA TM-X-71857, 1975

12. Kowalski, E. J. and Atkins, R. A. Jr.: A Computer Code for Estimating Installed Performance of Aircraft Gas Turbine Engines. Vol. III - Library of Inlet/Nozzle Configurations and Performance Maps, Boeing Military Airplane Company, December 1979

13. Libulkin, M.: Theoretical and Experimental Investigation of Additive Drag, NACA RM-E51813, 1951

14. Crosthwait, E. L., Kennon, L. G. Jr., Roland, H. L., et al: Preliminary Design Methodology for Air-Induction Systems. SEG-TR-67-1, General Dynamics, Fort Worth Division, AF(33)615-3125, 1967

15. Onat, E. and Klees, G. W.: A Method to Estimate Weight and Dimensions of Large and Small Gas Turbine Engines, Boeing Military Airplane Development, Seattle, Washington, January 1979, NASA CR-159981

16. Franciscus, L. C.: Interim Computer Program for Estimating Aircraft Engine Weight and Dimensions on a Component Basis, NASA TMX-73404, 1976

17. Morris, S. J. and Foss, W. E. Jr.: Assessment of Variable-Cycie Engines for Mach 2.7 Supersonic Transports: A Status Report, NASA TMX-73977, 1976

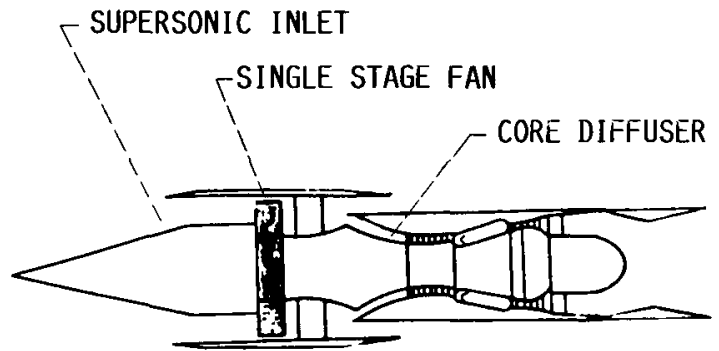

(A) SUPERSONIC THROUGH-FLOW FAN ENGINE.

SUBSONIC

DIFFUSER

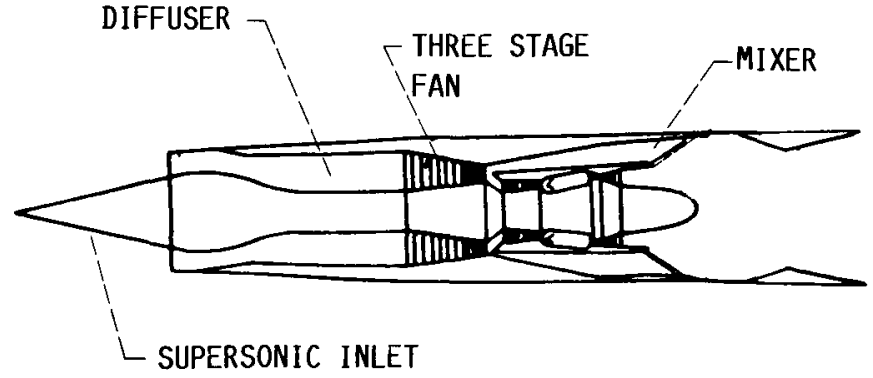

(B) CONVENTIONAL MIXED FLOW TURBOFAN ENGINE.

FIGURE 1. - ENGINE CONCEPTS. 


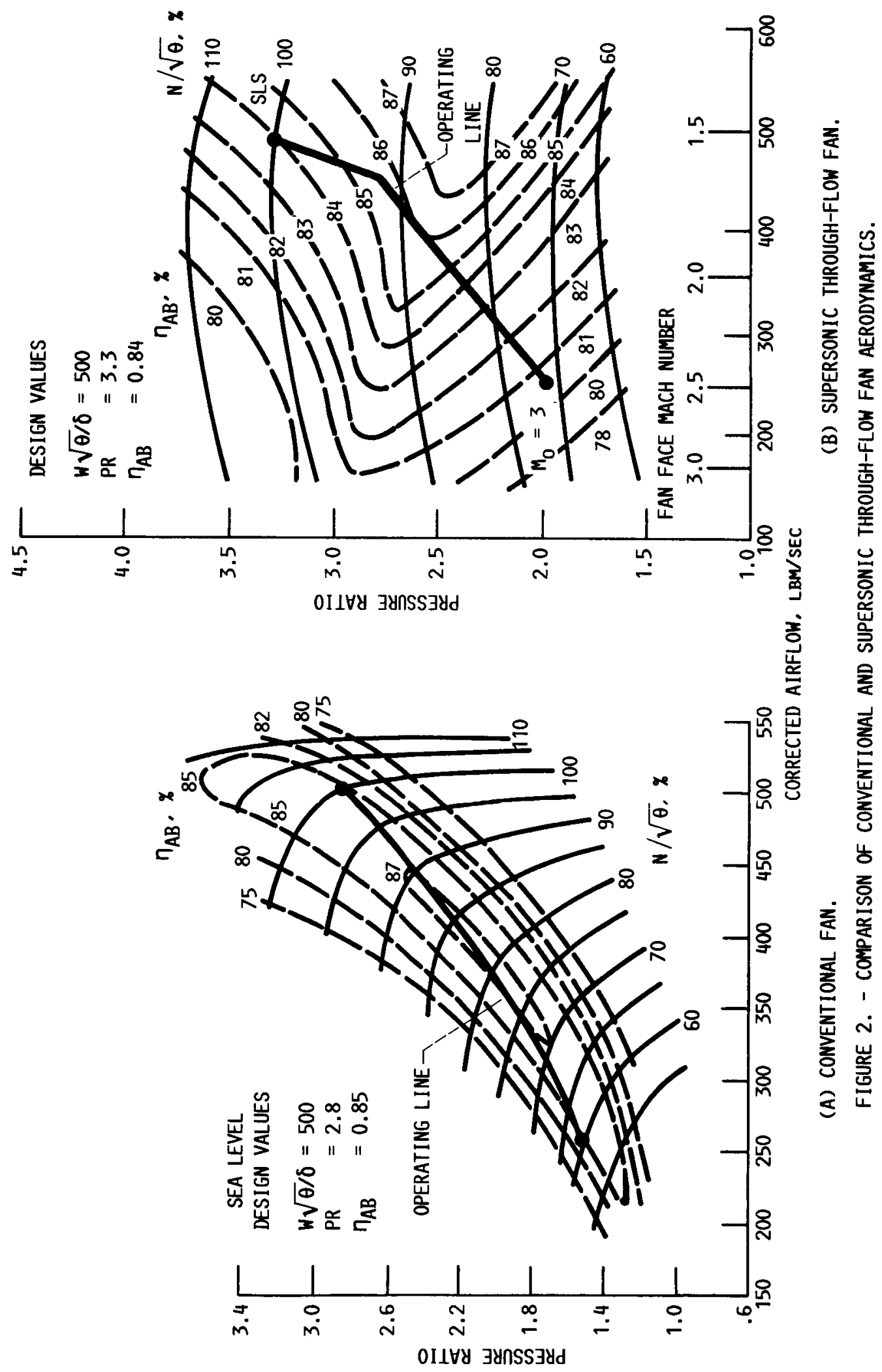




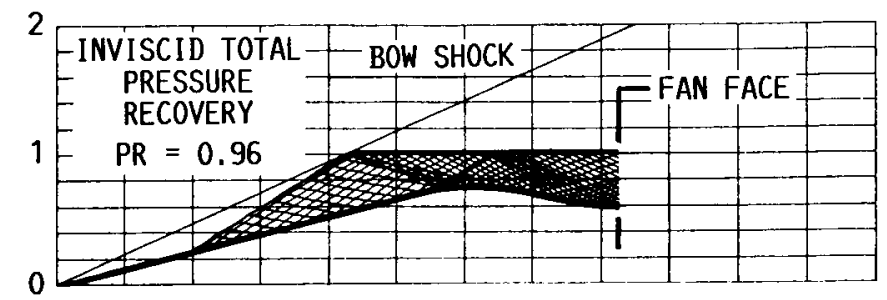

(A) VARIABLE AREA SUPERSONIC THROUGH-FLOW FAN INLET.

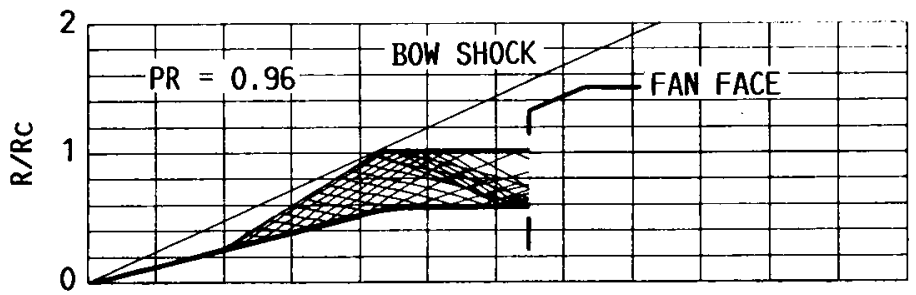

(B) CONSTANT AREA SUPERSONIC THROUGH-FLOW FAN INLET.

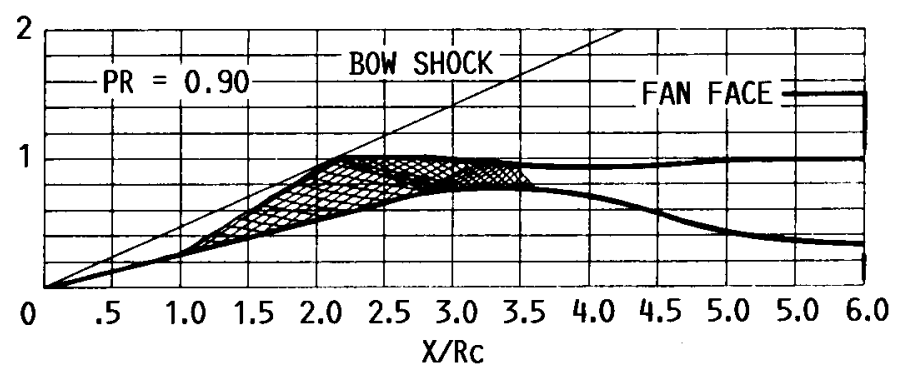

(C) CONVENTIONAL SUPERSONIC INLET.

FIGURE 3. - SUPERSONIC THROUGH-FLOW AND CONVENTIONAL INLETS DESIGNED FOR MACH 3. 

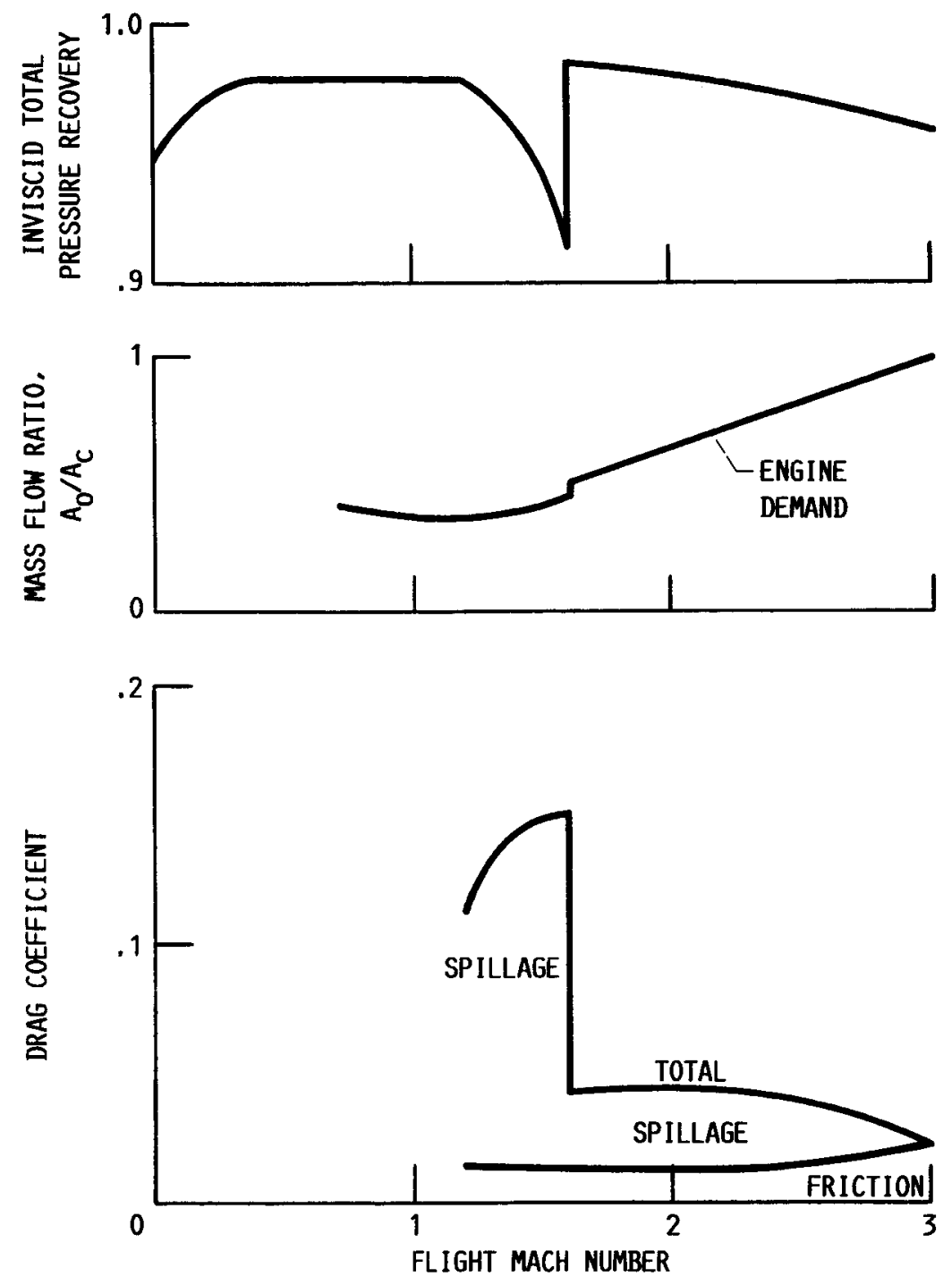

FIGURE 4. - SUPERSONIC THROUGH-FLOW INLET PERFORMANCE. 

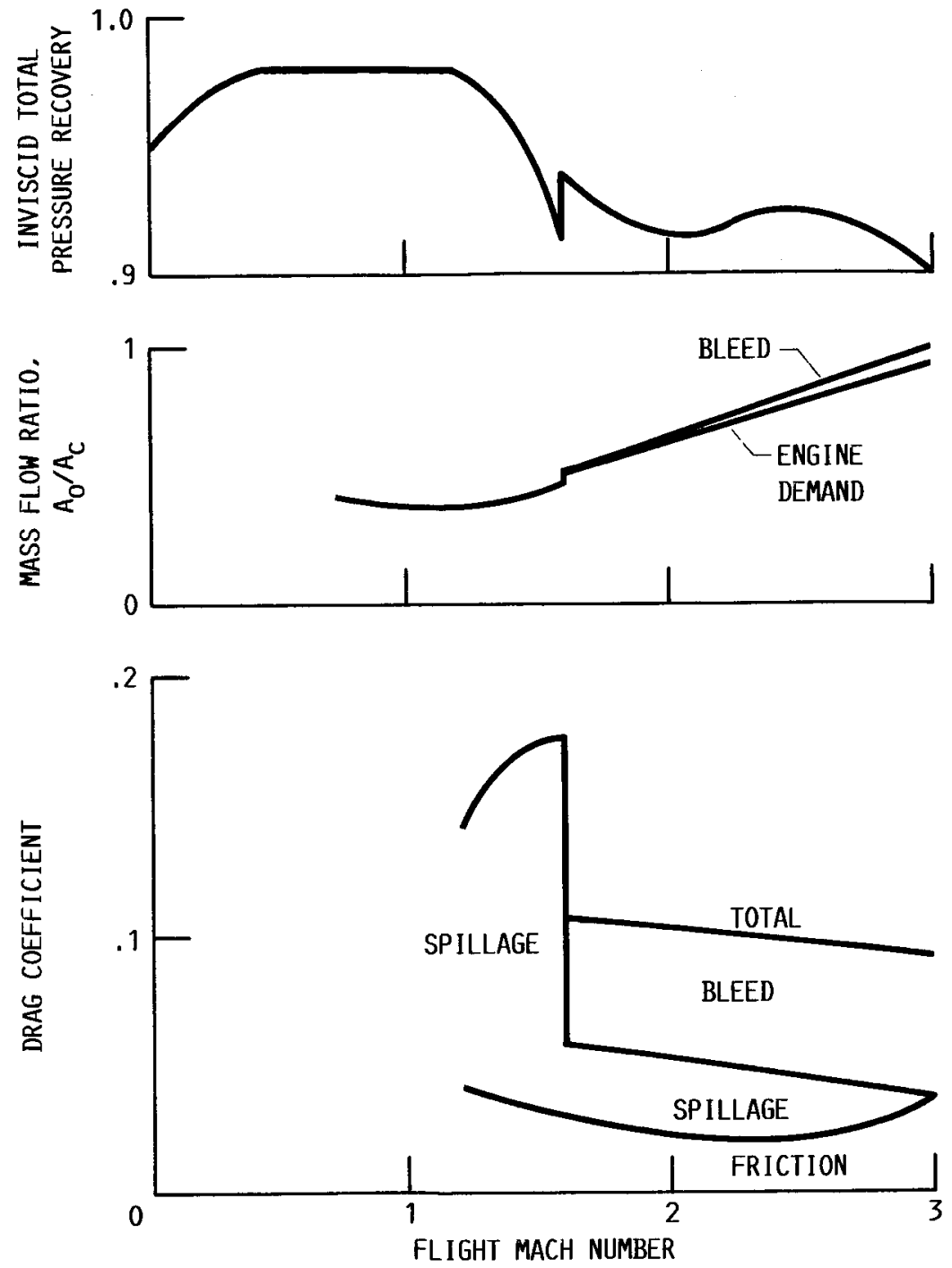

FIGURE 5. - CONVENTIONAL INLET PERFORMANCE. 

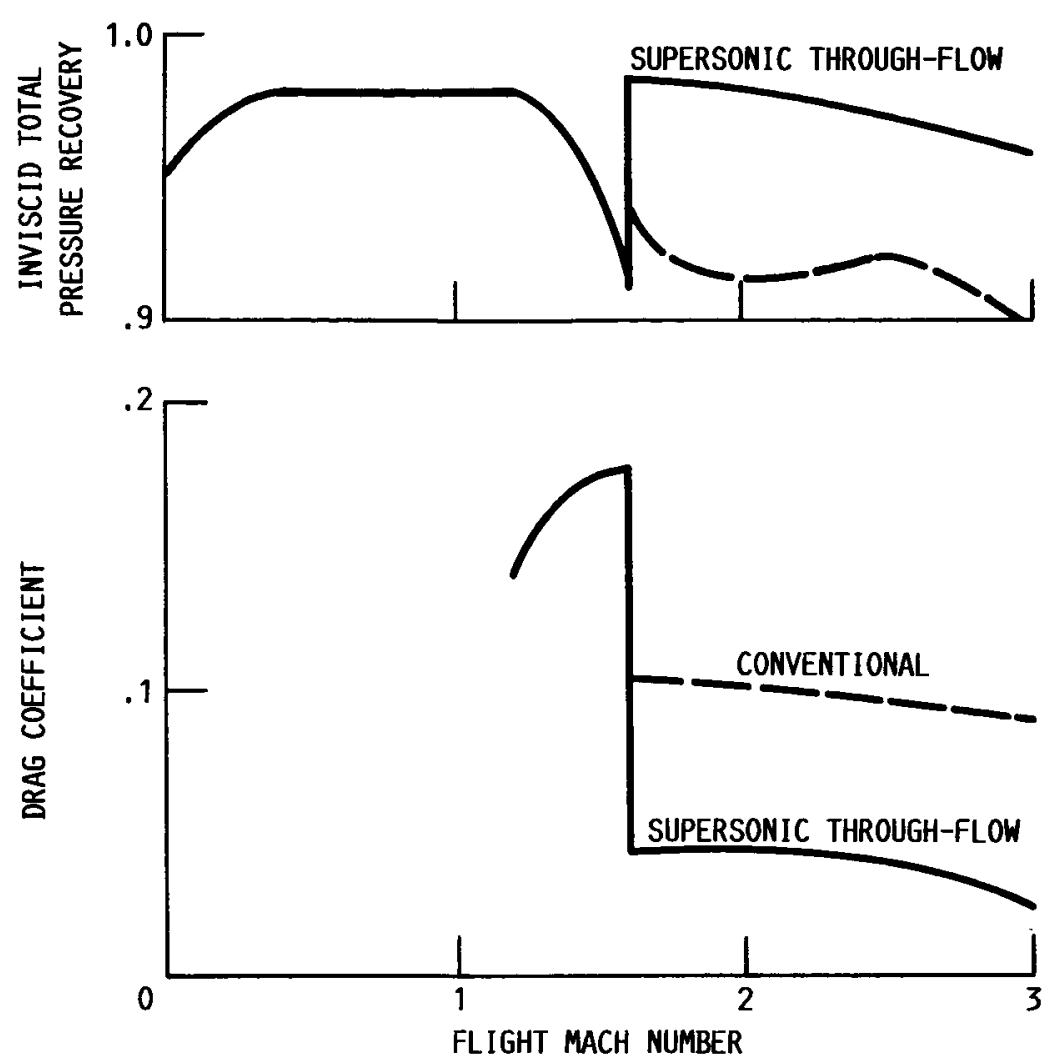

FIGURE 6. - COMPARISON OF CONVENTIONAL AND SUPERSONIC THROUGH-FLOW INLET PERFORMANCE.
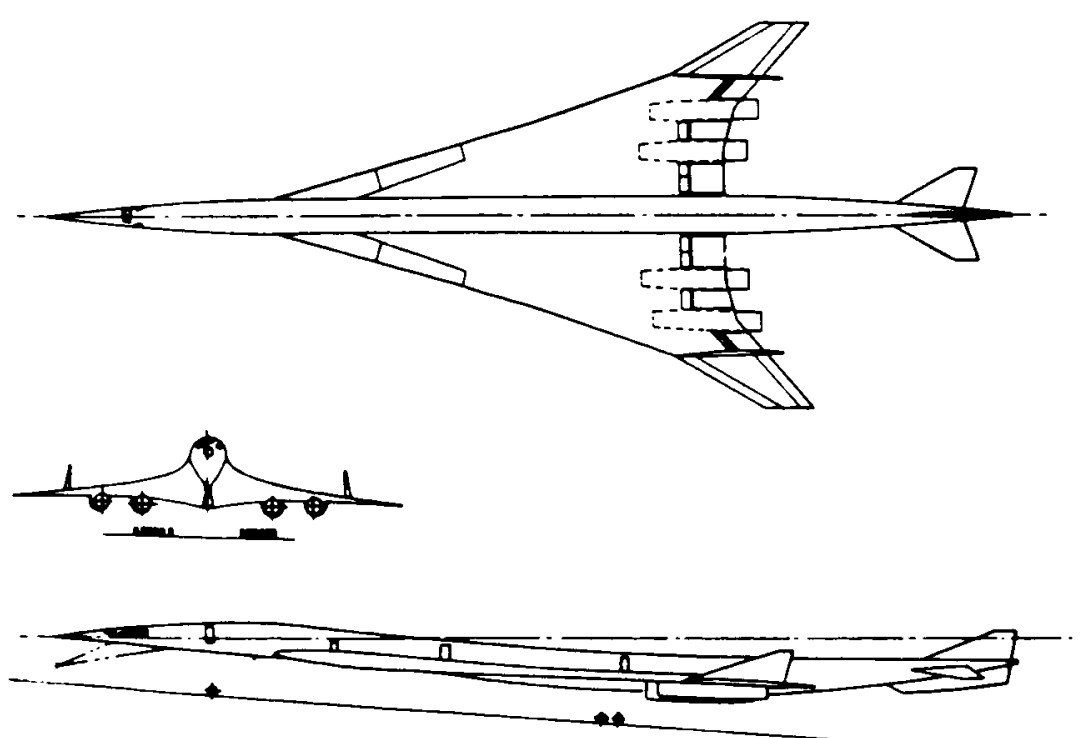

FIGURE 7. - GENERAL ARRANGEMENT OF THE AIRPLANE; CRUISE MACH NUMBER $=3:$ TOGW $=550000$ LBM: 292 PASSENGERS. 


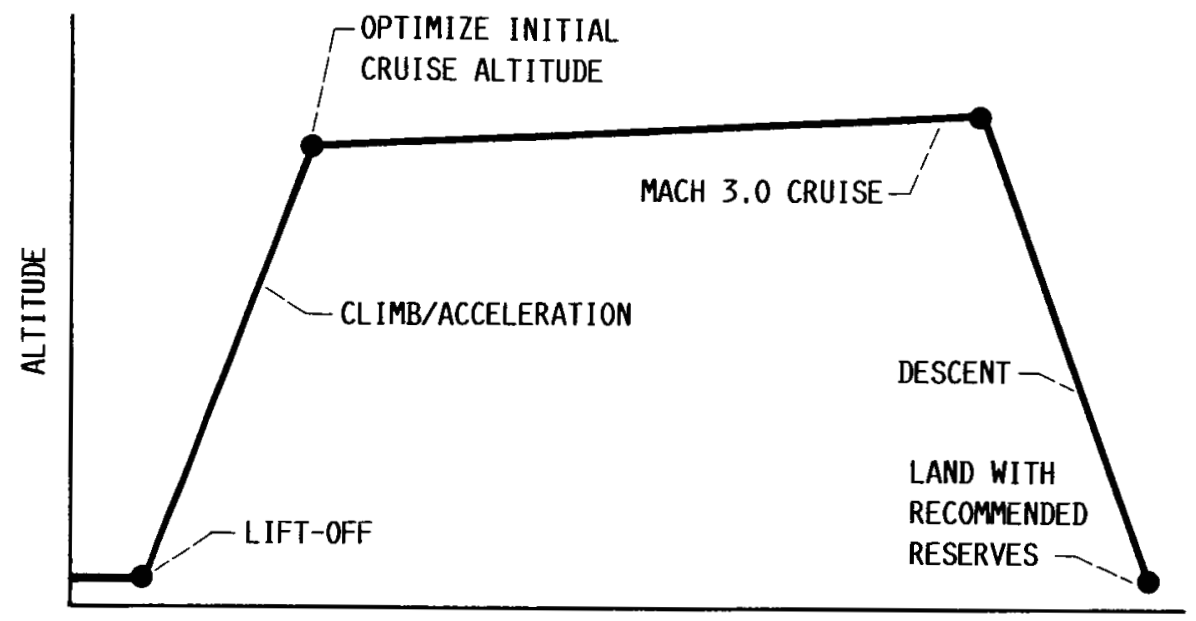

RANGE

FIGURE 8. - REFERENCE MISSION, STANDARD $+14.4{ }^{\mathrm{o}_{\mathrm{F}}}\left(+8{ }^{\circ} \mathrm{C}\right)$ DAY.

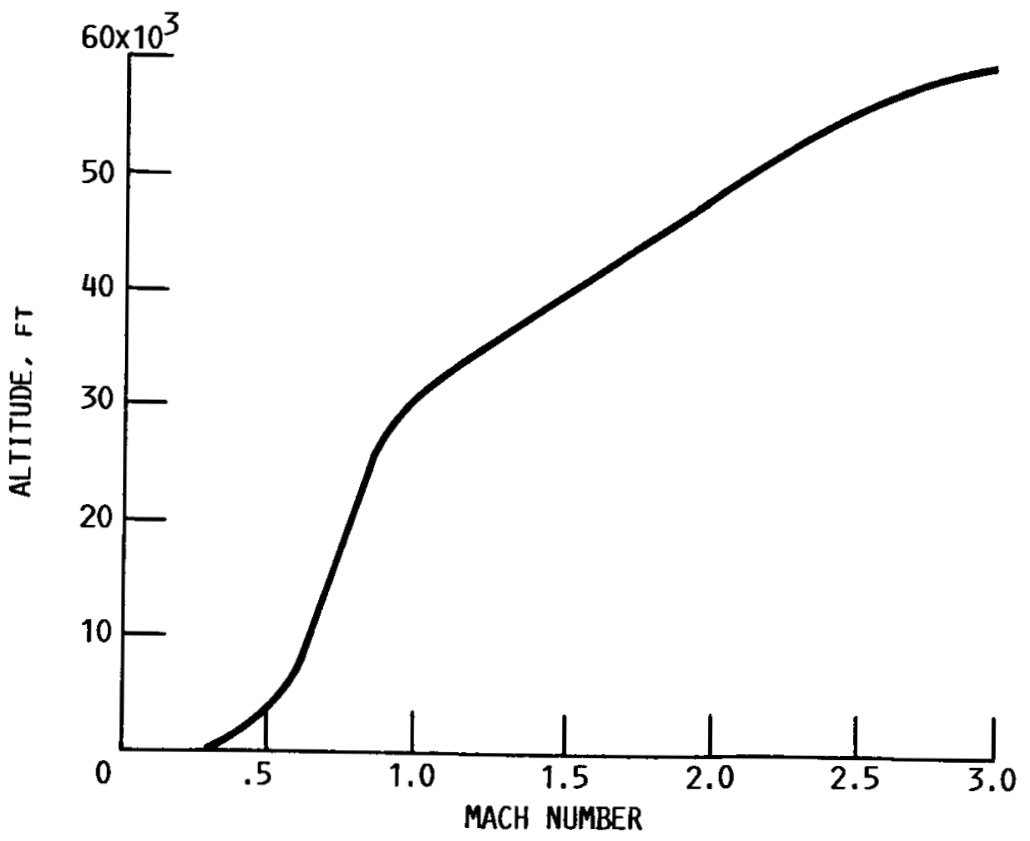

FIGURE 9. - FLIGHT PATH USED IN CLIMB/ACCELERATION. 


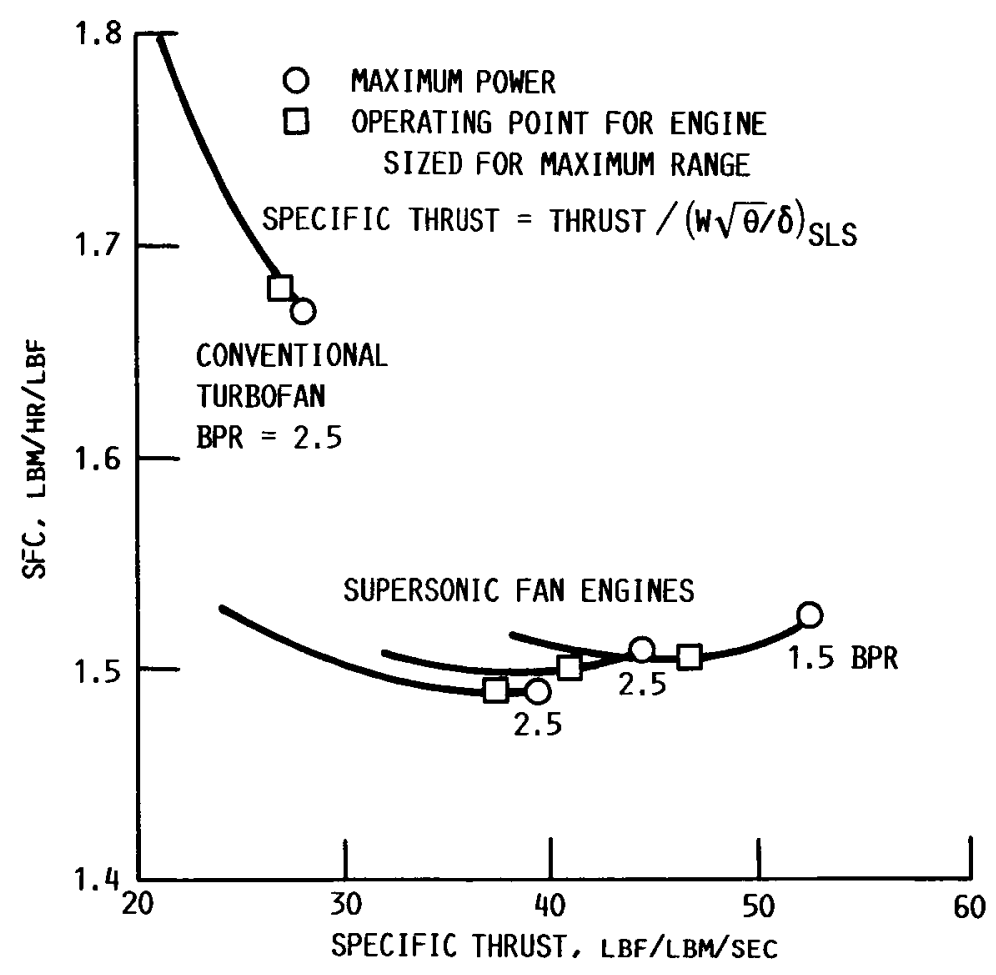

FIGURE 10. - COMPARISON OF SUPERSONIC THROUGH-FLOW FAN AND CONVENTIONAL FAN ENGINE PERFORMANCE: CRUISE MACH NUMBER $=3 ;$ ALTITUDE $=60000 \mathrm{FT}$.

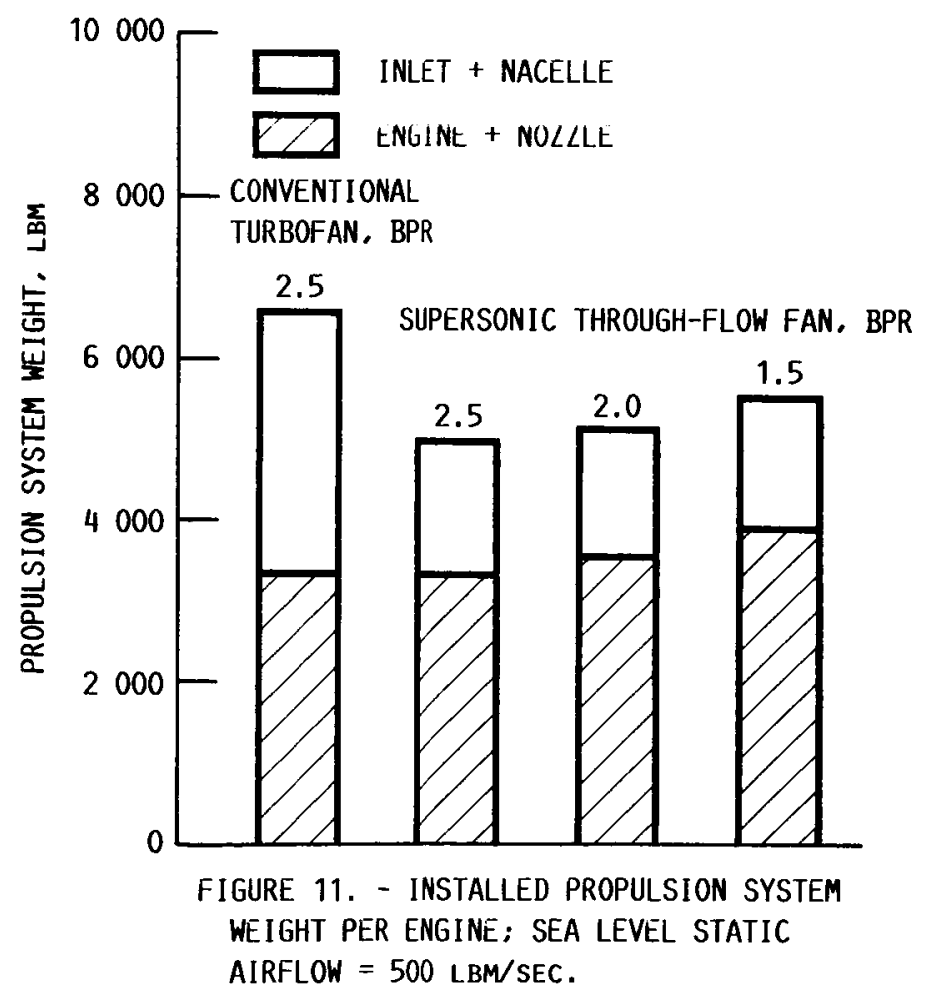




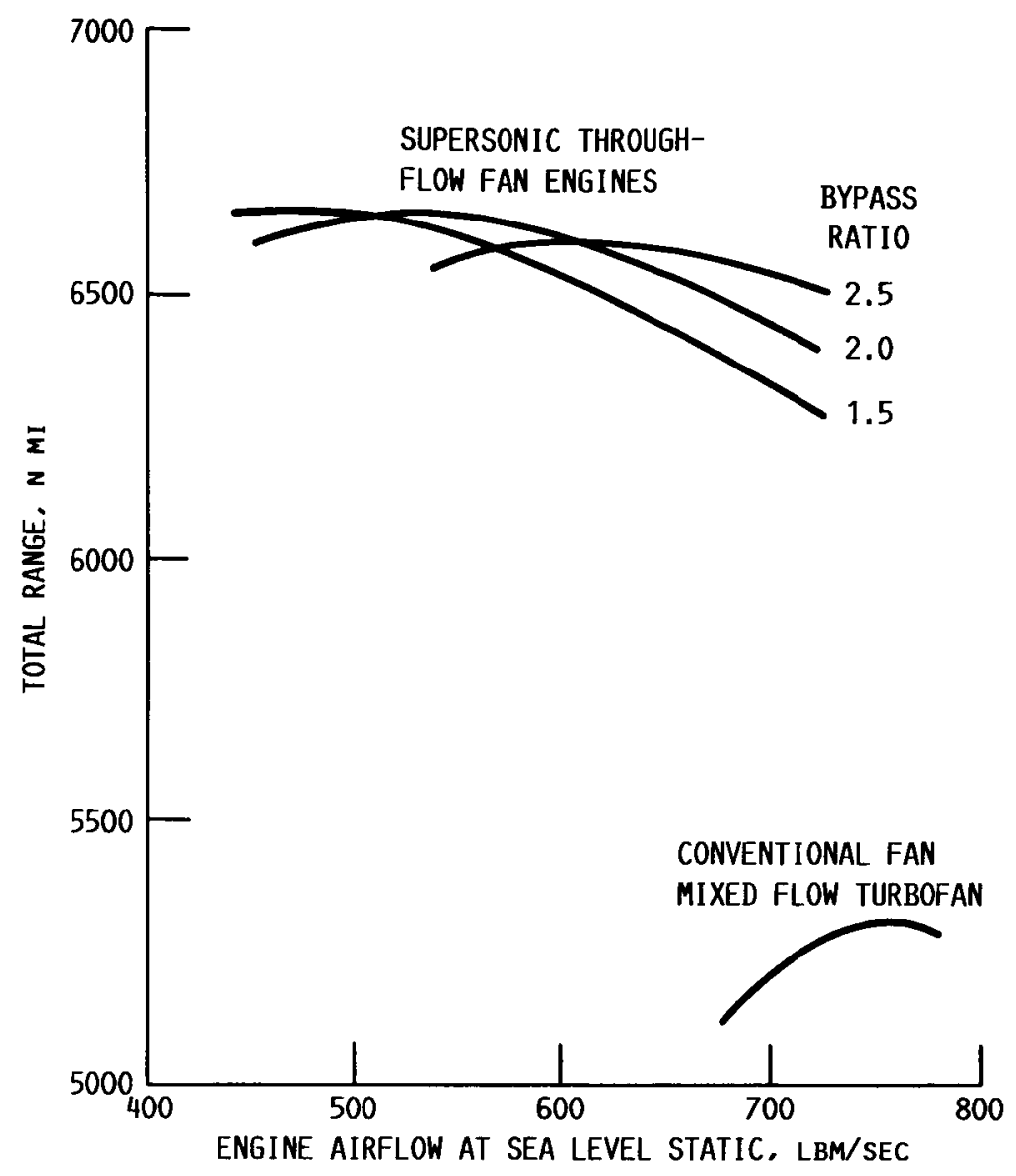

FIGURE 12. - COMPARISON OF MISSION RANGE OF SUPERSONIC THROUGH-FLOW FAN ENGINES AND CONVENTIONAL TURBOFAN ENGINES: TOGW = 550000 LBM: 292 PASSENGERS.

- fan performance

- inlet/Fan starting and Stability

- CORE INLET (TURBOFAN)

- SUPERSONic COMBUStion (FOR high maCh apPLICATION)

- BENEFITS FOR aLteRNATE aIRCRAFT/MISSIONS

FIGURE 13. - KEY SUPERSONIC THROUGH-FLOW ISSUES FOR RESEARCH. 


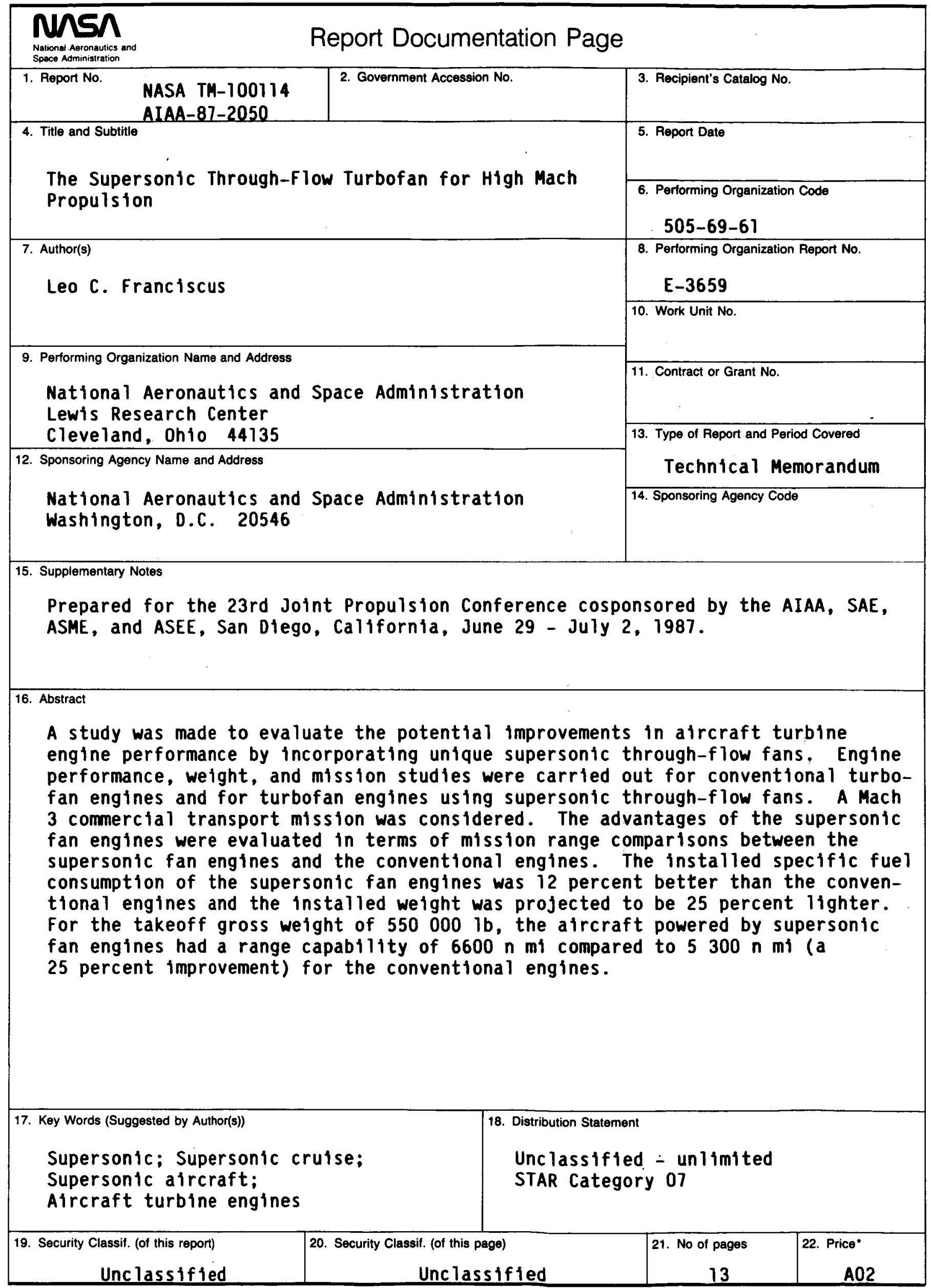

NASA FORM 1626 OCT $86 \quad$ "For sale by the National Technical Information Service, Springfield, Virginia 22161 